\title{
Women with Fibromyalgia: Association of Body Mass Index with Socioeconomic Status, Disease Severity, Functional Disability and Quality of Life
}

\author{
Raneyah H. M. Shaker1, Amal F. Soliman², Abd El-Wahab S. Elbrashy² \\ Ali I. Fouda ${ }^{2}$ and Sara M.Attia ${ }^{2}$
}

${ }^{1}$ Public Health and Community Medicine, ${ }^{2}$ Rheumatology, Rehabilitation and Physical Medicine Department. Faculty of Medicine, Benha university

Received: July 2016 Accepted: December 2016

\begin{abstract}
Fibromyalgia syndrome (FMS) may cause functional disability, severe pain and fatigue and affect quality of life (QoL)which interfere with daily activities of patients. Aim: To determine the association between body mass index (BMI) and symptom severity, QoL and functional capacity in patients with fibromyalgia. Participants and Methods: Fifty women (50) with fibromyalgia and thirty (30) age matched healthy women control group were assessed for BMI, socio-economic (SES) status assessment and clinical signs of fibromyalgia by FMS-related measurements, visual analogue scale (VAS), number of tender points (NTP) Fibromyalgia Impact Questionnaire (FIQ) and Myalgia score. The short form health survey - 36, Functional capacity was conducted by six minute walk test. Results: The majority of patients were obese (74\%): $48 \%$ class 1, 20\% class 2, and $6 \%$ class 3. Greater fibromyalgia-related symptoms and functional impairment were found in the higher BMI group with statistically significant differences regarding SES total score; education and culture total domain, NTP and myalgic score, 6 minutes' walk test, some domains of SF36 and leptin concentration. Severe FM showed higher VAS, NTP, Myalgic score, disease duration, BMI and leptin concentration but lower age and SES than other grades with statistically significant differences regarding disease duration VAS, myalgic score, leptin concentration and all SF36 domains except general health perception. Conclusion and Recommendation: The findings support that excess weight is negatively related to QOL, functional capacity, SES but positively related to disease severity (clinical and lab) in women with FMS. A fibromyalgia treatment program needs to incorporate medical and behavioral weight loss programs for obese patients
\end{abstract}

Key words: Fibromyalgia, BMI, women, QOL.

Corresponding author: Raneyah H.M.Shaker Email: ???

\section{Introduction}

Fibromyalgia (FM) is a debilitating, chronic illness characterized by chronic musculoskeletal widespread pain and a heightened and painful response to pressure $^{1}$. Associated somatic symptoms may occur with psychiatric and stressrelated disorders ${ }^{2}$.

Fibromyalgia symptoms may cause functional disability, severe pain and fatigue and affect QOL which interfere with daily activities of patients ${ }^{3}$ and account for the high indirect costs for society and an individual economic, social, educational and vocational burden ${ }^{4}$.

FM is a common disorder with a monthly incidence that has been shown to reach $9-10 \%$ in the general population $^{5,6}$ and $2-8 \%$ prevalence (3\% in women and $0.5 \%$ in men $)^{7}$. It is usually considered a disorder of women 
20-50 years, however it also occur in children, adolescents and older person ${ }^{8}$. Higher rates of people being overweight or obese, ranging from $47-73 \%$ have been reported in patients with fibromyalgia. BMI is an independent risk factor for fibromyalgia. Overweight or obese women had a 60-70\% higher risk compared with women of normal weight ${ }^{9}$.

Leptin is an adipocyte-derived hormone with evidence toward a role in the immune system and reduce the threshold for pain ${ }^{10}$. Its levels are influenced by BMI ${ }^{11}$.

Although obesity is common in patients with fibromyalgia, how the degree of obesity impacts fibromyalgia-related; clinical symptoms and lab profile (leptin levels) and QOL has not been reported to date. The purpose of the present study is to examine the association of BMI and socioeconomic status (SES), symptoms severity, QOL and functional capacity in patients with fibromyalgia and to evaluate the possibility of an alteration in levels of leptin patients suffering from fibromyalgia, a prototypical disorder of central pain processing

\section{Participants and Methods:}

This is a two phases study; phase one is a case control study which was carried out on fifty female patients with primary fibromyalgia who fulfilled the recent preliminary diagnostic Criteria for diagnosis of fibromyalgia syndrome ${ }^{12}$ referred from private clinics to the Rheumatology, Rehabilitation and Physical medicine outpatient clinic and inpatient department of Benha university hospitals, Egypt and another thirty healthy matched females as a control group with similar age, sociodemographic characteristics. The second stage is a descriptive cross sectional study conducted on the fifty female patients. This study was conducted according to the rules of
Benha faculty of medicine ethical committee. Informed consent was obtained from all women.

Inclusion criteria: Women with primary fibromyalgia from 18 to 55 years old.

Exclusion criteria include other autoimmune diseases, severe chronic disabling conditions as severe complicated diabetes mellitus (DM) or hypertension (HTN) and malignancies, history of psychological disorders prior to diagnosis of FM, Family history of psychological disorders.

Females have been investigated by a number of lab tests to exclude other syndromes of pain.

Females included in this study were subjected to BMI assessment: It was calculated as weight in kilogram divided by square of the height in meters, BMI was classified to underweight $<18.5$, normal BMI (18.5-24.9), over weight (25-29.9) and obesity into class I (BMI $30.0-34.9 \mathrm{~kg} / \mathrm{m}^{2}$ ), class II (BMI 35.0$39.9 \mathrm{~kg} / \mathrm{m}^{2}$ ), and class III (BMI -40.0 and more $\left.\mathrm{kg} / \mathrm{m}^{2}\right) .{ }^{13}$

Data Collection Tool of: A number of validated self-administered questionnaire were used. Participants received instructions about how to complete them with the aid of researcher.

\section{A- Socio economic data:}

It was recorded using a self-report social score. Additional information as date of birth, and time since FM diagnosis were also included. Social score is used to assess the socioeconomic status (SES). It was calculated according to El Gilany et al., $2012^{14}$

The final scale included 7 domains with a total score of 84 , with a higher score indicating better SES. Socioeconomic level was classified into four levels depending on the quartiles of the score calculated $^{14}$.

\section{B-FMS-Related Measurements:}

1- Visual analogue scale (VAS): Widespread Pain will be assessed by

$\begin{array}{llll}\text { Vol. } 35 & \text { No. } 3 & \text { July } & 2017\end{array}$


pain score $(0-10 \mathrm{~cm})$, with higher scores indicating more pain. The score was obtained by measuring the line in centimeters from 0 to the point marked by the patient. ${ }^{15}$

2- Number of tender points (NTP): It would be determined by applying a pressure with the thumb on 18 specific body points, and the NTP was recorded 16

3- Myalgic score (MS): is a rating given by the physician to describe the sensitivity of a tender point when pressure is applied. The physician determined the number of active tender points and rated the sensitivity of the pain on a scale of 0 (no pain) to 3 (withdrawal of the patient from the examiner) of each tender point to determine a myalgic score ${ }^{17}$.

\section{4-Serum leptin:}

It is measured using commercial ELISA kit DBC (diagnostic Biochem Canda Inc. Cat. No. CAN-L-4260.

\section{C -Assessment of disability quality of life and current health status: \\ 1- Fibromyalgia Impact Questionnaire}

(FIQ): It measures multiple domains of fibromyalgia symptoms and functional impairment based on the reported severity of symptoms. A higher score indicates a greater impact of the syndrome on the person. The maximum possible score is 100 . The average FM patient scores about 50, severely afflicted patients are usually 70 plus ${ }^{18}$.

2-The short -form health survey 36:(SF-36) It is a generic instrument ;including physical and mental components and monitoring patient outcomes. It assesses 8 dimensions. The SF-36 score ranges from $0-100$, and higher scores indicate better health status and less disability, where 0 indicates the worst possible health status and 100 the best possible ${ }^{19}$.

\section{D-Functional capacity:}

Six minute walk test is used for objective assessment of functional performance. The subjects were instructed to walk their maximum distance in a 6-min period. The total distance covered in meters during the 6 min of walking was used as the score for each session ${ }^{20}$.

\section{Statistical analysis:}

The collected data were tabulated and analyzed using SPSS version 16 soft ware. The data were expressed as mean and standard deviation for continuous data and number and percentages for numerical data. continuous variables were compared across the BMI groups through one way analysis of variance (ANOVA). The accepted level of significance in this work was 0.05 (2 sided $\mathrm{P}$ value $<0.05$ was considered significant).

\section{Results}

This study included 2 groups patients group and control group. The socioeconomic score of the patients' group was $50.94 \pm 12.07$ versus $53.5 \pm 19.2$. of the control group while the mean age of the patients' group is $34.7 \pm 9.5$ versus $33.6 \pm 7.6$ years of the control group The mean body mass index of the patients' group is $32.9 \pm 6.5$ and of the control group is $33.4 \pm 4.9$ with statistically non-significant results $(\mathrm{p}<0.05)$.

The mean leptin concentration of the patients were $37.4 \pm 10.4$ compared with $29.3 \pm 11.3$ of the control with statistically significant results. There were differences between control group and patient group regarding SF-36 different components and 6 minutes' walk test with statistically significant results $(\mathrm{p}<0.001)$.

Further Comparison between obese FM patients and obese control are conducted.

Socio economic scores domains of the study sample by groups are presented in figure 1. Groups showed significant 
differences only on family possession and family domain.

Health-related QOL of FM patients and obese control groups are shown in figure 2.

All the dimensions of QOL, as measured by SF-36 subscales, were significantly worse in the obese FM patients group compared to the obese control group $(p<0.001)$.

Comparison of the functional capacity of the two groups are showed in figure 3.

Functional capacity test (six minute walk test) were significantly impaired in obese FM patients group compared to the obese control group ( $p<0.001)$.

The majority of patients were obese (74\%) distributed as (48\%) class 1, $(20 \%)$ class 2 , and $(6 \%)$ class 3 , there were statistically significant differences between patients' body mass index categories regarding SES total score ( $p$ $<0.05)$ and education and culture total domain $(\mathrm{p}<0.001)$.

Obesity grade I showed a higher (total socio-economic scale, education and culture) scores than normal weight and other grades of obesity.(table 1)

FIQ score, NTP, VAS, myalgic score, functional capacity and leptin concentration comparison by BMI category are reported in Table2. There were significant group differences except for VAS ( $p>0.05$ ).

Obesity grade III showed higher VAS, myalgic score, NTP, FIQ Score and leptin concentration. While Normal weight showed higher 6 minute walk test than other obesity grades (Table 2).

Health-related QOL as expressed by SF36 by obesity status is shown in Table 3.

There are, group differences with the lower SF-36 scores in the higher BMI groups indicating poorer QOL in all subscales except for physical function, physical component summary, physical role and bodily pain no significant differences between obesity status groups were found. Normal weight showed higher (physical function, pain index, general health perception, vitality, social function, physical component) than other obesity grades (Table 3).

Regarding severity of fibromyalgia, more than half $(56 \%)$ of patients were average to high grade with equal distribution $(22 \%)$ of the other grades; below average and severe.

Disease duration, BMI, VAS, NTP, Myalgic score , 6 minute walk test and leptin concentration were worse across grades of severity of FM (table 4).

Severe grade of FM showed higher(VAS, NTP, Myalgic score and leptin concentration) but lower age and SES while below average FM showed the highest score of 6 minute walk test with statistically significant differences for disease duration, VAS, myalgic score and leptin concentration .

Also table 4 reveals inverse relation between grades of fibromyalgia, age and SES with non-significant differences .

Association between grades and SF36 domains were presented in table 5 . There were statistically significant difference regarding different domains of SF36except for general health perception $(p>0.05)$.

Below average FM showed higher scores for all domains than other grades of FM severity (Table 5).

\section{Discussion}

Clinical studies of FM patients indicate that it is a complex medical condition with chronic symptoms that is often refractory to treatment ${ }^{21}$. Identifying factors which exacerbate or improve FMS symptoms is essential with the absence of a cure or treatments that completely alleviate symptoms ${ }^{22}$.

This study was conducted on females with primary fibromyalgia aged (18-55) years. According to Carmona et al. ${ }^{23} \mathrm{FM}$ appeared to be related to age, it is

Vol. $35 \quad$ No. $3 \quad$ July 2017


uncommon in the extremes aged subjects and is more prevalent in women of the childbearing age. In various studies, median age of patients was reported between $(27-46)$ years. ${ }^{24}$

Women are more likely than men to develop fibromyalgia ${ }^{7}$ while Siedel and Muller $2011^{25}$ showed that women are only 1.6 times more likely to develop FMS than men. This relationship may be explained by biological, hormonal and social factors ${ }^{26}$.

FM patients had worse physical performance than healthy group They reported a greater pain intensity and perception of effort. This agrees with many studies $27,28,29$.

This study revealed that Obesity is common in patients with fibromyalgia, the majority of our patients $(74 \%)$ were obese. Different studies supported the association between FMS and increased BMI. ${ }^{30,31}$

Potential mechanisms that may explain the association between fibromyalgia and obesity include a higher level of pain receptors in fat tissue, alterations in the endogenous opioid system, elevated serum levels of pro inflammatory cytokines, thyroid dysfunction and increased mechanical loads associated with greater BMI. ${ }^{32}$

This study revealed that obesity grade III showed lower (total socio-economic scale, education and culture, economic domains) than normal weight and other grades of obesities and lower socio economic score was associated with more severe symptoms of FMS this agrees with many studies. ${ }^{33,34}$

Karlson et al., $1997^{35}$ reported that patients with FM and lower SES as measured by lower level of education had greater symptom severity, worse quality of life and poorer function than with higher education. Also Rakeovski et al., $2012^{36}$ stated that higher income and education were associated with fewer symptoms of FM.
The association between fibromyalgia and lower socioeconomic status population could be explained by the tendency to be overweight, to work in more manual jobs and to do more household work which may facilitate more pain and injuries. ${ }^{37}$

Regarding relation of age with symptom severity our results agree with Bathaii et al., $2006^{38}$ who reported that symptom severity differ across age groups in patients with fibromyalgia, with young and middle-aged patients having poorer and worse fibromyalgia symptoms than do older patients.

This study showed that increasing of BMI leading to significant increasing of FM symptoms severity, myalgic score, FIQ score, NTP and significant decreasing of some SF 36 domains.

This agrees with others 9, 29,39 who approved that greater BMI is associated with higher levels of fibromyalgia symptoms and pain, as well as lower levels of QOL but Neumann et al. (2008) ${ }^{40}$ observed no differences.

This study revealed that main score of VAS measuring average pain intensity was high in patients with non-significant difference between cases by BMI categories which were relatively the same results recorded by Orellana et al.(2008) ${ }^{41}$ and Schaefer et al. (2011) ${ }^{42}$. Morbidly obese patients with FM had a significantly higher frequency of low back and musculoskeletal pain than lean patients. $^{43}$

FIQ is the most widely used tool for measuring quality of life in patients with FM according to Assumpcao et al., 2010. ${ }^{44}$

In our study total score of FIQ was significantly increased in obese fibromyalgia patients grade III which agree with many studies. ${ }^{9,45,46}$

However Yunus et al., $2002{ }^{47} \mathrm{did}$ not identify specific differences in self reported score of FIQ across obesity grades. 
Our results of leptin concentration showed agreement with the study of Fietta and Fietta ${ }^{11}$ finding significantly higher leptin level in FM patients than control.

In contrast, Ablin et al. (2012) ${ }^{48}$ and Olama et al. (2013) ${ }^{49}$ found no significant difference between leptin level among FM patients and control and also found no significant correlation between leptin level and clinical parameters reflecting FM severity.

Differences across weight status categories on SF36, were observed in our study; BMI had negative impact on SF 36 and worse SF 36 values mainly in over weight and obese compared to normal weight are recorded. This came in accordance with others. ${ }^{45,50,51,52}$

Our study showed that increasing of BMI is associated with higher levels of fibromyalgia symptoms. Also disease duration, visual analogue scale [VAS], (more pain intensity and increase fatigue) and myalgic score were significantly increase in sever FM patients.

The association of symptom severity with severe or morbid obesity also has been noted in other conditions. ${ }^{30}$ Morbidly obese patients had significantly higher frequency of low back and other musculoskeletal pain than lean patients, and the lowest QOL scores were observed in the morbidly obese patients compared with other BMI strata. ${ }^{51,53}$

In survey by Schaever et al. (2011) ${ }^{42}$ it was reported that FM severity level was very important for evaluation of FM treatment and priority setting of health care.

Musculoskeletal symptoms, functional disability and QOL, as well as fibromyalgia symptoms in overweight and obese, have been shown to improve with weight reduction measures.

\section{Conclusion}

Obesity is common in patients with fibromyalgia, $74 \%$ of our patients were obese and $6 \%$ were severely obese A greater BMI is associated with higher levels of fibromyalgia symptoms and pain, as well as lower levels of QOL and physical performance, higher VAS and Myalgic score than non obese or overweight patients.

\section{Recommendations:}

Keeping a normal-weight status and to avoid overweight or obese status could be a useful way to improve FM patients symptoms, QOL, and functional capacity. Fibromyalgia treatment program needs to incorporate weight loss strategies, including lifestyle changes with proper diet and increased physical activity. It is recommended to conduct further investigation about other risk factors affecting symptoms severity of fibromyalgia and perform more researches for the impact of loss of weight as a treatment of FMS.

Future studies with more number may be enhanced to promote comparison between healthy control groups classified by BMI categories.

\section{References}

1. Ngian GS, Guymer EK and Littlejohn GO (2011): The use of opioids in fibromyalgia. Int $\mathrm{J}$ Rheum Dis; $\quad 14$ (1): 6-11. https://en.wikipedia.org/wiki/Digital_ob ject_identifier

2. Schweinhardt P, Sauro KM and Bushnell MC (2008):Fibromyalgia: a disorder of the brain? Neuroscientist; 14 (5): 415-21.

3. Shapiro JR, Anderson DA, DanoffBurg S (2005): A pilot study of the effects of behavioral weight loss treatment on fibromyalgia symptoms. J Psychosom Res; 59: 275-82.

4. Henriksson CM, Liedberg GM and Gerdle B (2005): Women with fibromyalgia: work and rehabilitation. Disabil Rehabil; 27: 685-94. 
5. Wolfe F, Ross K, Anderson J, Russell IJ and Hebert L (1995): The prevalence and characteristics of fibromyalgia in the general population. Arthritis Rheum; 38:19-28.12

6. Croft P, Rigby AS, Boswell R, Schollum J and Silman A (1993): The prevalence of chronic widespread pain in the general population. J Rheumatol; 20:710-713.

7. White KP, Speechley M, Harth M, et al. (2000): Co-existence of chronic fatigue syndrome with fibromyalgia syndrome in the general population a controlled study. Scand J. Rheumatol.; 29:44-51.

8. Neumann L and Buskila D (2003): Epidemiology of Fibromyalgia. Curr. Pain Headache Rep.; 7:362-368.

9. Zhang Y, Proenca R, Maffei M, Barone M, Leopold L and Friedman JM (1994): Positional cloning of the mouse obese gene and its human homologue.Nature.;372:425-32.

10. Calapai G, Corica F, Corsonello A, et al. (1999): Leptin increases serotonin turnover by inhibition of brain nitric oxide synthesis. J Clin Invest.;104:97582. [PMC free article] [PubMed]

11. Fietta $P$ and Fietta $P$ (2006): Counterbalance between leptin and cortisol may be associated with fibromyalgia. Psychiatry ClinNeurosci.;60:529.

12. Wolfe F, Clauw DJ, Fitzcharles MA, et al. (2010): The American College of Rheumatology preliminary diagnostic criteria for fibromyalgia and measurement of symptom severity. Arthritis Care Res.; 62(5):600-610.

13. World Health Organization (2000): Obesity: preventing and managing the global epidemic. Report of a WHO consultation. World Health Organ Tech Rep Ser; 894: i-xii, 1-253.

14. El-Gilany A,1 El-Wehady A and. El-Wasify M (2012): Updating and validation of the socioeconomic status scale for health research in Egypt. EMHJ. Volu 18, issue 9.
15. Mc Caffery M and Pasero C (1999): Teaching patients to use onumerical pain- rating scale. Am J Nurse.; 99 (12): 22.

16. Wolfe F, Clauw DJ, Fitzcharles MA, et al. (2011): Fibromyalgia criteria and severity scales for clinical and epidemiological studies: a modification of the ACR Preliminary Diagnostic Criteria for Fibromyalgia. J Rheumatol; 38(6):1113-22.

17. Panton LB, Kingsley JD, Toole T, Cress ME, Abboud G, Sirithienthad P, et al. (2006): A comparison of physical functional performance and strength in women with fibromyalgia, ageand weight-matched controls, and older women who are healthy PhysTher; 86(11):1479-88.

18. Bennett R (2005): The Fibromyalgia Impact Questionnaire (FIQ): a review of its development, current version, operating characteristics and uses. Clin.Exp. Rheumatol.;23: 154162.

19. Ware JE Jr and Sherbourne CD (1992):The MOS 36-item short-form health survey (SF- 36). I. Conceptual framework and item selection. Med. Care, 30: 473-83.

20. Jones CJ, Rutledge DN and Aquino J (2010): Predictors of physical performance and functional ability in people 50+ with and without fibromyalgia. J Aging Phys Act; 18(3): 353-68.

21. Hawley DJ, Wolfe F and Cathey MA (1988):Pain, functional disability, and psychological status: a 12-month study of severity in fibromyalgia. J Rheumatol; 15:1551-1556.

22. Sueiro Blanco F, Estévez Schwarz I, Ayán C, et al., (2008):Potential benefits of non-pharmacological therapies in fibromyalgia. The Open Rheumatology Journal; 2:1-6.

23. Carmona L, Ballina J, Gabriel R. et al., (2001):On behalf of the EPISER Study Group. The burden of musculoskeletal diseases in general

$\begin{array}{llll}\text { Vol. } 35 & \text { No. } 3 & \text { July } & 2017\end{array}$


population of Spain: results from a national survey. Ann. Rheum. Dis;60:1040-1045.

24. NilaySahin, Aziz Atik, Erdal Dogan (2014): Clinical and demographic characteristics and functional status of the patients with fibromyalgia syndrome, North Clin Istanbul;1(2):8994.

25. Siedel, MF and Muller W (2011):Differential pharmacotherapy for subgroups of fibromyalgia patients with specific consideration of 5-HT3 receptor antagonists. Expert Opin Pharmacother; 12(9): 1381-1391.

26. Santos AM, Burti JS, Lopes JB et al.(2010): Prevalence of fibromyalgia and chronic widespread pain in community-dwelling elderly subjects living in São Paulo, Brazil. 67(3): 251255.

27. Homann D, Stefanello JM, Góes SM and Leite N (2011): Impaired functional capacity and exacerbation of pain and exertion during the 6-minute walk test in women with fibromyalgia. Rev Bras Fisioter;15(6):474-80.[Links]

28. Cardoso F de S, Curtolo M, Natour J and Lombardi Júnior I (2011): Assessment of quality of life, muscle strength and functional capacity in women with fibromyalgia. Rev Bras Reumatol; 51(4):338-43,349-50.

29. Mannerkorpi K, Svantesson U and Broberg C (2006):Relationships between performance-based tests and patients' ratings of activity limitations, self-efficacy, and pain in fibromyalgia. Arch Phys Med Rehabil; 87(2):259-64.

30. Mork PJ, Vasseljen $\mathrm{O}$ and Nilsen TI (2010): Association between physical exercise, body mass index, and risk of fibromyalgia: longitudinal data from the Norwegian Nord-Trondelag Health Study. Arthritis Care Res (Hoboken); 62: 611-7.

31. Castro S, Poveda MJ, Fontova R, et al. (2013): Obesity and fibromyalgia: Relationship between body mass index and severity of the symptoms. Ann Rheum Dis; 71: 700.

32. Ursini F, Naty S and Grembiale RD (2011): Fibromyalgia and obesity: the hidden link. Rheumatol Int; 31: 1403.

33. Blyth FM, March LM, Brnabic AJ, Jorm LR, Williamson $M$ and Cousins MJ (2001):Chronic pain in Australia: a prevalence study. Pain; 89: 127-34.

34. Brekke M, Hjortdahl P and Kvien TK (2002):Severity of musculoskeletal pain: relations to socioeconomic inequality. SocSci Med., 54: 221-228. 10.1016/S0277-9536(01)00018-1

35. Karlson EW,Daluoy LH,Lew RA, WrightEA, PartridgeAJ,Fossel AH,et al. (1997): The relationship of socioecnomic status, race and modifiable risk factors to outcomes in patients with systemic lupus. Arthritis Rheum; 40:47-56.

36. RakovskiC,Zettel-WastonL and RutledgeD (2012):Association of employment and working conditions with physical and mental health symptoms for people with fibromyalgia. DisabilRehabil;34:1277-83.

37. Wijnhoven $\mathrm{HAH}$, de Vet HCW and H. Picavet SJ (2006): Explaining sex differences in chronic musculoskeletal pain in a general population. Pain.2006, 124: $\quad 158-66 . \quad 10.1016 /$ j.pain. 04.012.View Article PubMed Google Scholar

38. Jiao J, Vincent A, Cha SS, Luedtke CA, Oh TH (2014) : Relation of age with symptom severity and quality of life in patients with fibromyalgia. Mayo Clin Proc. 2014 Feb;89(2):199-206. doi: 10.1016/j.mayocp.2013.09.021.

39. Timmerman GM, Gayle M, Calfa NA, et al. (2013): Correlates of body mass index in women with fibromyalgia. Orthop Nurs; 32(2): 113119

40. Neumann L, Lerner E, Glazer Y, et al. (2008): A cross-sectional study of the relationship between body mass index and clinical characteristics, tenderness measures, quality of life, and physical 
functioning in fibromyalgia patients. Clin Rheumatol; 27: 1543-7.

41. Orellana C, Casado E, Masip M, et al., (2008):Sexual dysfunction in fibromyalgia patients. Clin.Experi. Rheumatol., 26: 663-666.

42. Schaefer C, Chandran A, Hufstader M, Baik R, McNett M, Goldenberg D, et al. The comparative burden of mild, moderate and severe fibromyalgia: results from a cross-sectional survey in the United States. Health Qual Life Outcomes 2011;9:71.

43. Melissas J, Volakakis E and Hadjipavlou A (2003): Low-back pain in morbidly obese patients and the effect of weight loss following surgery. ObesSurg;13:389-93.

44. Assumpção A, Sauer JF, Mango PC and Pascual Marques A. (2010): Physical function interfering with pain and symptoms in fibromyalgia patients. Clin Exp Rheumatol 2010;28(Suppl 6):57-63.

45. Kim C, Luedtke CA, Vincent A, et al. (2012): Association of body mass index with symptom severity and quality of life in patients with fibromyalgia. Arthritis Care and Research; 6(2): 222-228.

46. Jia $\mathrm{H}$ and Lubetkin EI (2005): The impact of obesity on health-related quality-of-life in the general adult US population. J Public Health; 27:156-64. 47. Yunus MB, Arslan S and Aldag JC (2002): Relationship between body mass index and fibromyalgia features. Scand J Rheumatol 31:27-31.

48. Ablin JN, Buskila D, Van Houdenhove B et al.(2012): Is fibromyalgia a discrete entity? Autoimmunity Reviews;11: 585-588.

49. Olama SM, Elsaid TO and ElArman M (2013): Serum leptin in Egyptian patients with fibromyalgia syndrome: Relation to disease severity. International Journal of Rheumatic Diseases; 16: 583-589.

50. Arranz L, Canela MA and Rafecas M (2012): Relationship between body mass index, fat mass, and lean mass with sf-36 quality of life scores in a group of fibromyalgia patients. Rheumatol Int 32:3605-3611

51. Okifuji A, Bradshaw DH and Olson C (2009): Evaluating obesity in fibromyalgia: neuroendocrine biomarkers, symptoms, and functions. Clin .Rheumatol; 28: 475-8.

52. A paricio VA, Ortega FB, Carbonell-Baeza A, Camiletti D, Ruiz JR, Delgado-Fernandez M (2011): Relationship of weight status with mental and physical health in female fibromyalgia patients. Obes Facts 4:443-448.

53. Vincent HK, Lamb KM, Day TI, Tillman SM, Vincent KR and George SZ (2010): Morbid obesity is associated with fear of movement and lower quality of life in patients with knee painrelated diagnoses. PM R; 2:713-22. 
Table (1): Comparison of BMI categories of patients group regarding the Socioeconomic scale domains.

\begin{tabular}{|l|c|c|c|c|c|c|}
\hline & $\begin{array}{c}\text { Normal } \\
(\mathbf{4})\end{array}$ & $\begin{array}{c}\text { Overweigh } \\
(\mathbf{9})\end{array}$ & $\begin{array}{c}\text { Obesity I } \\
(\mathbf{2 4})\end{array}$ & $\begin{array}{c}\text { Obesity II } \\
(\mathbf{1 0})\end{array}$ & $\begin{array}{c}\text { Obesity III } \\
(\mathbf{3})\end{array}$ & $\mathbf{p}$ \\
\hline SES score & $43.3 \pm 8.5$ & $45.1 \pm 12.3$ & $55.6 \pm 9.4$ & $51.7 \pm 14.4$ & $38.3 \pm 0.6$ & $<0.05^{*}$ \\
\hline $\begin{array}{l}\text { Education } \\
\text { \&culture }\end{array}$ & $13.5 \pm 5.3$ & $15.6 \pm 7.6$ & $20.8 \pm 6$ & $17 \pm 6$ & $4.3 \pm 1.5$ & $<0.001^{*}$ \\
\hline $\begin{array}{l}\text { Family } \\
\text { domain }\end{array}$ & $6.3 \pm 1$ & $6.1 \pm 1.5$ & $6.5 \pm 1.4$ & $7 \pm 1.2$ & $6.7 \pm 0.7$ & $>0.05$ \\
\hline $\begin{array}{l}\text { Economic } \\
\text { domain }\end{array}$ & $2 \pm 0.1$ & $2.1 \pm 0.3$ & $2.5 \pm 0.7$ & $2.7 \pm 0.9$ & $2 \pm 0.01$ & $>0.05$ \\
\hline $\begin{array}{l}\text { Occupational } \\
\text { domain }\end{array}$ & $2.7 \pm 1$ & $4 \pm 1.9$ & $5.1 \pm 2.5$ & $4.3 \pm 1.6$ & $3.3 \pm 0.6$ & $>0.05$ \\
\hline $\begin{array}{l}\text { Family } \\
\text { possession }\end{array}$ & $6.8 \pm 1.5$ & $5.9 \pm 1.3$ & $8.3 \pm 2$ & $7.5 \pm 2$ & $8.3 \pm 3$ & $>0.05$ \\
\hline $\begin{array}{l}\text { Home } \\
\text { sanitation }\end{array}$ & $7.8 \pm 1$ & $7.8 \pm 2.1$ & $8.7 \pm 1.2$ & $8.9 \pm 2.3$ & $9.7 \pm 0.7$ & $>0.05$ \\
\hline $\begin{array}{l}\text { Health care } \\
\text { domain }\end{array}$ & $4.3 \pm 1.5$ & $4 \pm 1.2$ & $4 \pm 1.4$ & $4.2 \pm 1.3$ & $4 \pm 1.4$ & $>0.05$ \\
\hline
\end{tabular}


Table (2): Comparison of BMI categories of patients group regarding some fibromyalgia related clinical and lab measures.

\begin{tabular}{|l|c|c|c|c|c|c||}
\hline & Normal (4) & $\begin{array}{c}\text { Overweight } \\
(\mathbf{9})\end{array}$ & $\begin{array}{c}\text { Obesity I } \\
(\mathbf{2 4})\end{array}$ & $\begin{array}{c}\text { Obesity II } \\
(\mathbf{1 0})\end{array}$ & $\begin{array}{c}\text { Obesity III } \\
\mathbf{( 3 )}\end{array}$ & P \\
\hline VAS & $5.5 \pm 0.6$ & $5.9 \pm 0.9$ & $6 \pm 1$ & $6.3 \pm 1.1$ & $6.7 \pm 0.6$ & $>0.05$ \\
\hline NTP & $16.2 \pm 2.3$ & $17.3 \pm 1.5$ & $17.7 \pm 1.5$ & $18 \pm 1.4$ & $18.6 \pm 0.7$ & $<0.05^{*}$ \\
\hline $\begin{array}{l}\text { Myalgic } \\
\text { score }\end{array}$ & $28.5 \pm 5.4$ & $30.5 \pm 9.1$ & $32.4 \pm 9.3$ & $36.3 \pm 9.4$ & $43.3 \pm 5.5$ & $0.01 *$ \\
\hline FIQ score & $50.4 \pm 11.4$ & $63.6 \pm 9.1$ & $61.3 \pm 9.7$ & $62.3 \pm 7$ & $74.3 \pm 7.3$ & $0.01 *$ \\
\hline 6mwtest & $295 \pm 5.7$ & $282.7 \pm 18.7$ & $254.8 \pm 28.6$ & $251.8 \pm 44.8$ & $211 \pm 46$ & $<0.001^{*}$ \\
\hline $\begin{array}{l}\text { Leptin } \\
\text { concentration }\end{array}$ & $19.6 \pm 6.2$ & $19 \pm 5.7$ & $34.9 \pm 11$ & $57.9 \pm 17.3$ & $66.9 \pm 19.1$ & $<0.001 *$ \\
\hline
\end{tabular}

Table (3): Comparison of BMI categories of patients group regarding different SF-36 domains.

\begin{tabular}{|l|c|c|c|c|c|c|}
\hline & $\begin{array}{c}\text { Normal } \\
\mathbf{( 4 )}\end{array}$ & $\begin{array}{c}\text { Overweight } \\
(\mathbf{9})\end{array}$ & $\begin{array}{c}\text { Obesity } \\
\text { I (24) }\end{array}$ & $\begin{array}{c}\text { Obesity } \\
\text { II (10) }\end{array}$ & $\begin{array}{c}\text { Obesity } \\
\text { III (3) }\end{array}$ & p \\
\hline $\begin{array}{l}\text { Physical } \\
\text { function pain }\end{array}$ & $66.3 \pm 7.5$ & $41.7 \pm 10.6$ & $39.6 \pm 10.3$ & $35 \pm 8.5$ & $33.3 \pm 5.7$ & $<0.001 *$ \\
\hline $\begin{array}{l}\text { Bodily } \\
\text { (pain index) }\end{array}$ & $41.3 \pm 11.8$ & $20.9 \pm 5.6$ & $21.6 \pm 6.2$ & $23.2 \pm 8$ & $40.7 \pm 12.1$ & $<0.05^{*}$ \\
\hline $\begin{array}{l}\text { General health } \\
\text { perception }\end{array}$ & $33.5 \pm 11.1$ & $24.4 \pm 9.2$ & $32.4 \pm 11$ & $19.9 \pm 7.2$ & $23 \pm 1.7$ & $>0.05$ \\
\hline Vitality & $41.3 \pm 11$ & $31.7 \pm 5$ & $39.2 \pm 12$ & $39.5 \pm 11.2$ & $26.7 \pm 2.3$ & $>0.05$ \\
\hline Social function & $40.5 \pm 18$ & $20.8 \pm 7.1$ & $23.5 \pm 3.3$ & $12.5 \pm 4.3$ & $4.2 \pm 0.8$ & $>0.05$ \\
\hline $\begin{array}{l}\text { Mental health } \\
\text { index }\end{array}$ & $18 \pm 5.8$ & $28.9 \pm 7.5$ & $16.2 \pm 3.9$ & $18 \pm 4$ & $9.3 \pm 3.6$ & $>.05$ \\
\hline $\begin{array}{l}\text { Mental } \\
\text { component } \\
\text { summary }\end{array}$ & $23.1 \pm 1.9$ & $25.8 \pm 6.4$ & $23.9 \pm 7.8$ & $23.5 \pm 2.5$ & $18.1 \pm 0.1$ & $>0.05$ \\
\hline $\begin{array}{l}\text { Physical } \\
\text { component } \\
\text { summary }\end{array}$ & $40.3 \pm 2.8$ & $31 \pm 3.9$ & $32.8 \pm 4.8$ & $30.5 \pm 2.8$ & $33.8 \pm 0.8$ & $<0.001 *$ \\
\hline
\end{tabular}


Table (4): Comparison of grades of severity of FM of the patients group regarding age, BMI and some fibromyalgia related clinical and lab measures.

\begin{tabular}{|l|c|c|c|r|}
\hline & $\begin{array}{c}\text { Below average } \\
(\mathbf{1 1})\end{array}$ & $\begin{array}{c}\text { Average to } \\
\text { high(28) }\end{array}$ & $\begin{array}{c}\text { Severe } \\
(\mathbf{1 1})\end{array}$ & \multicolumn{1}{|c|}{ P } \\
\hline Age & $34.5 \pm 3$ & $32.9 \pm 9.3$ & $28.9 \pm 7.8$ & $>0.05$ \\
\hline $\begin{array}{l}\text { Disease } \\
\text { duration }\end{array}$ & $1.7 \pm 0.7$ & $2.5 \pm 0.6$ & $3.9 \pm 0.9$ & $<0.001^{*}$ \\
\hline BMI & $27.7 \pm 4.3$ & $30.8 \pm 4$ & $33 \pm 5.2$ & $>0.05$ \\
\hline SES & $51.5 \pm 13.1$ & $50.6 \pm 14.2$ & $49.6 \pm 6.9$ & $>0.05$ \\
\hline *VAS & $5.1 \pm 0.4$ & $6.2 \pm 1$ & $6.3 \pm 0.7$ & $0.001^{*}$ \\
\hline NTP & $17.1 \pm 1.9$ & $17.3 \pm 1.8$ & $18 \pm 1.2$ & $>0.05$ \\
\hline Myalgic score & $26.2 \pm 6.4$ & $32.6 \pm 6$ & $38.9 \pm 6.6$ & $>0.001^{*}$ \\
\hline 6m.w.test & $271.3 \pm 33.2$ & $255 \pm 38.5$ & $246.9 \pm 41.6$ & $>0.05$ \\
\hline $\begin{array}{l}\text { Leptin } \\
\text { concentration }\end{array}$ & $23.5 \pm 8.8$ & $40.4 \pm 13.6$ & $41.6 \pm 12.5$ & $0.04 *$ \\
\hline
\end{tabular}

Table (5): Comparison of grades of severity of FM of the patients' groups regarding Sf-36 domains.

\begin{tabular}{|l|c|c|c|r|}
\hline \hline & $\begin{array}{c}\text { Below average } \\
(\mathbf{1 1})\end{array}$ & $\begin{array}{c}\text { Average to high } \\
\mathbf{( 2 8 )}\end{array}$ & $\begin{array}{c}\text { Severe } \\
(\mathbf{1 1})\end{array}$ & P \\
\hline Physical function & $53.2 \pm 11.2$ & $39.5 \pm 10.6$ & $31.9 \pm 9.3$ & $<0.001^{*}$ \\
\hline Role physical health & $90.9 \pm 27.3$ & $66.1 \pm 21.3$ & $18.1 \pm 6.2$ & $0.001^{*}$ \\
\hline Bodily pain (pain index) & $67 \pm 18$ & $58 \pm 19.2$ & $30 \pm 9.3$ & $0.002^{*}$ \\
\hline $\begin{array}{l}\text { General } \\
\text { perception }\end{array}$ & $69.2 \pm 19.4$ & $57 \pm 18.2$ & $46.4 \pm 15.3$ & $>0.05$ \\
\hline Vitality & $54.5 \pm 12.3$ & $52.8 \pm 16.2$ & $38.2 \pm 15.2$ & $0.02^{*}$ \\
\hline Social function & $74.5 \pm 17.2$ & $54.8 \pm 18.3$ & $29.4 \pm 9.7$ & $0.005^{*}$ \\
\hline Mental health index & $50 \pm 5.9$ & $46 \pm 15.9$ & $27.5 \pm 10.1$ & $0.002^{*}$ \\
\hline $\begin{array}{l}\text { Mental component } \\
\text { summary }\end{array}$ & $50.4 \pm 5.5$ & $46 \pm 9.4$ & $39 \pm 9.4$ & $0.02^{*}$ \\
\hline $\begin{array}{l}\text { Physical component } \\
\text { summary }\end{array}$
\end{tabular}




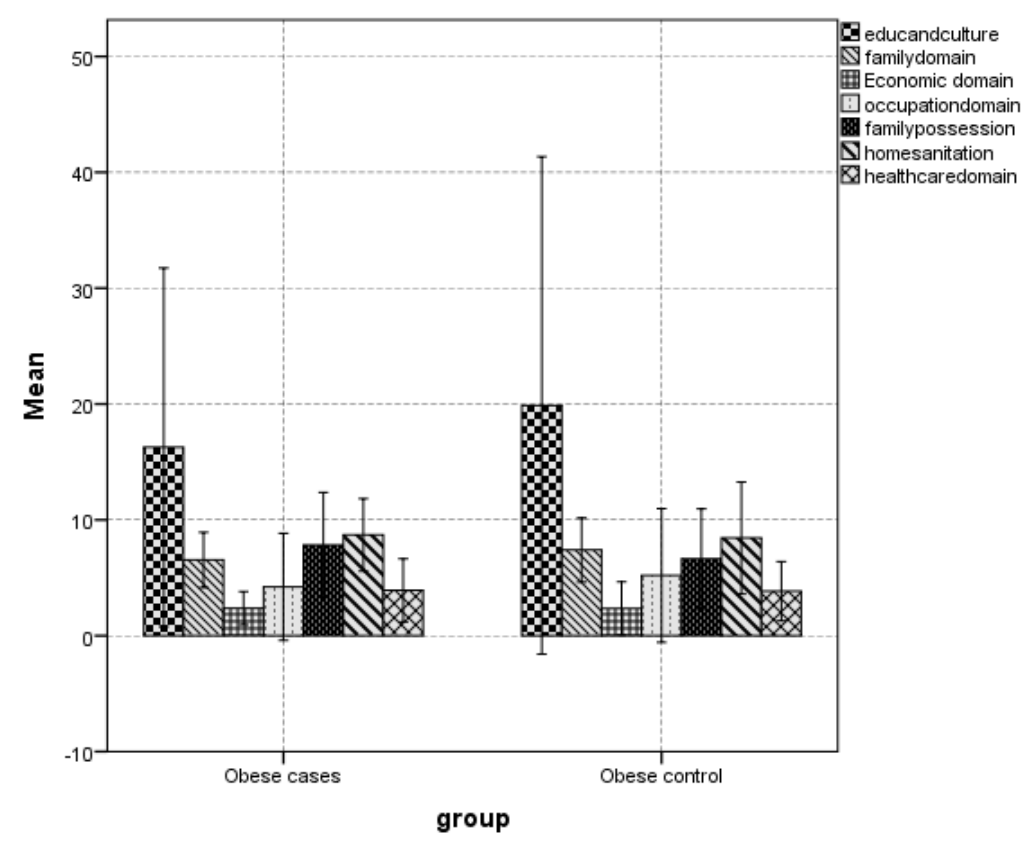

Figure (1): Comparison of SES domains among obese patients and obese control

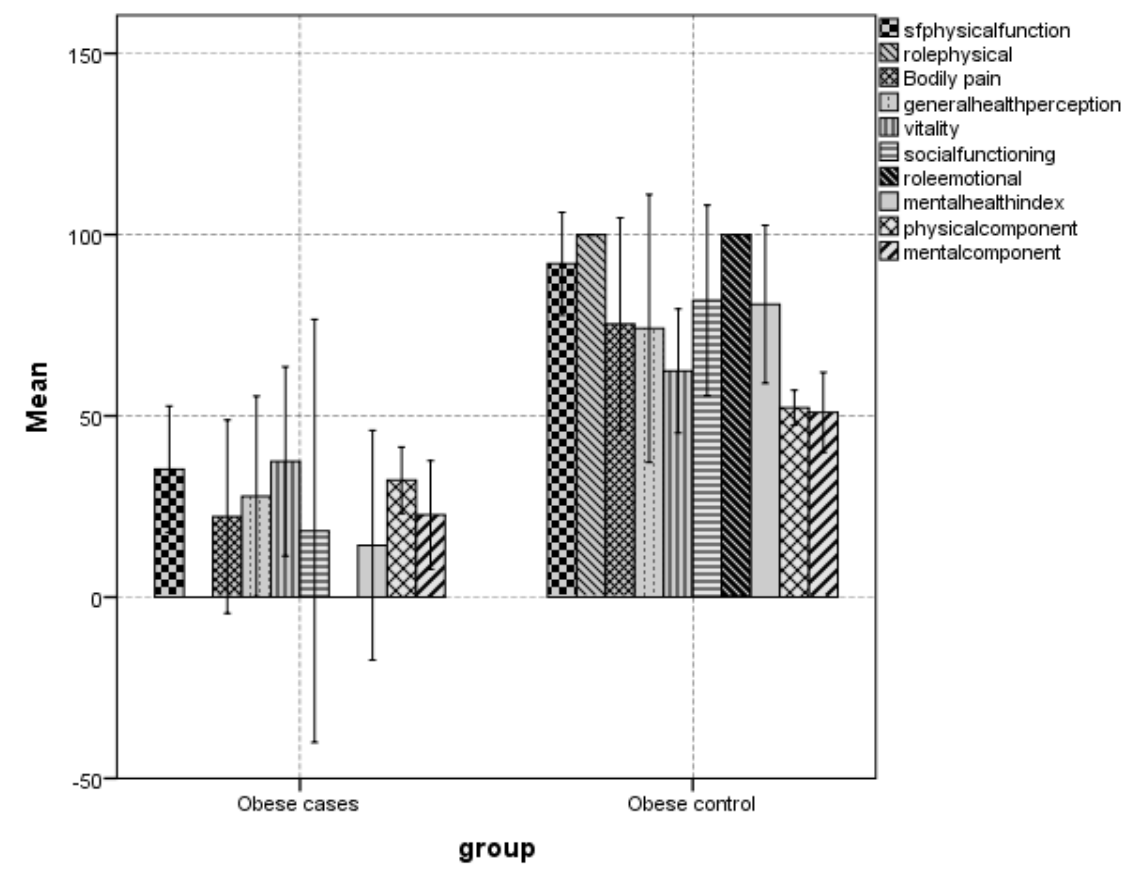

Figure (2): Comparison between obese cases and obese control as regard SF 36 different domains. 


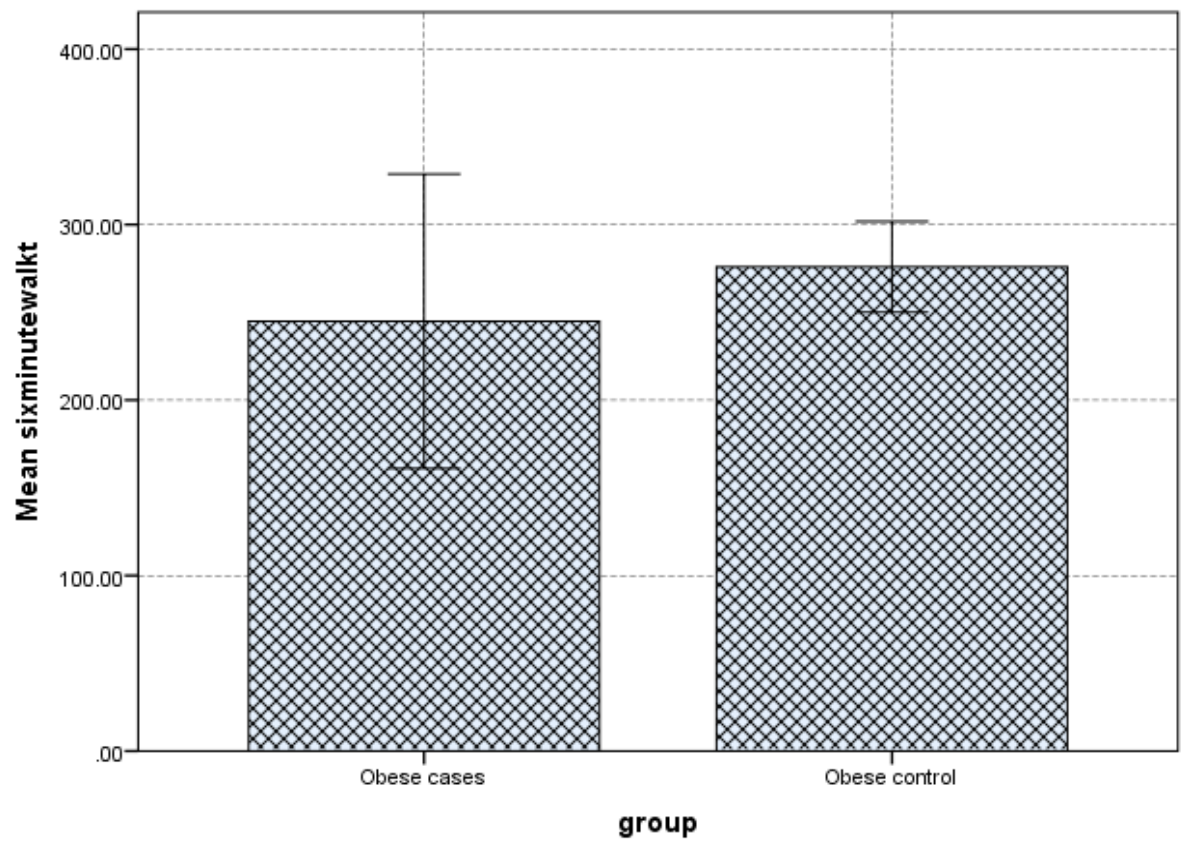

Figure (3): Comparison between obese cases and obese control as regard functional capacity assessment 